\title{
A TOC Approach To Setup Reduction To Improve Agility
}

\author{
Bernardo Villarreal, Universidad de Monterrey, Mexico
}

\begin{abstract}
Setup reduction has been one of the main programs to improve a firm's performance in terms of response time and flexibility. The selection and sequence of setup reduction projects takes importance in a multi-product, multi-machine environment with limited resources. This paper describes a Theory of Constraints (TOC) based approach to deal with the previous situation when the goal is to improve agility. Results of this application to a Mexican company is provided.
\end{abstract}

\section{INTRODUCTION}

乌

$\mathrm{n}$ order to meet the requirements for price, quality, response time and flexibility of today's competitive global market, most firms have implemented advanced technologies and philosophies such as Flexible Manufacturing Systems and Just in Time manufacturing.

Flexibility is the key characteristic of an agile supply chain. In fact, the concept of agility emerges from the development of flexible manufacturing systems (FMS). The idea of a manufacturing system being highly responsive to changes in product mix or volume was extended a wider context at the supply chain level (Nagel, et al., 1991).

Setup time reduction programs have been one of the main components of manufacturing performance improvement strategies. The prioritization of setup investment projects in a multi-product, multi-machine resourceconstrained environment is of major concern, and in particular if our objective is to become faster and more flexible to respond to customer's requirements. The most suggested approach to attack this situation is the use of Pareto analysis of total setup time in a period (Hall 1983), (Shingo 1985). Even though this insures that investment efforts are assigned to the machine with the largest setup time, it does not make sure that the systems' performance as a whole is improved.

This paper proposes a general scheme that will assist management to rank setup reduction projects with the goal of maximizing overall systems' performance measured in terms of response time reduction. The following section provides a review of the literature that deals with works related with the reduction of setup and manufacturing lead time and describes the approach considered in this paper to rank setup reduction efforts. Section 3 provides the results of the use of simulation to define a setup reduction strategy for a Mexican company that fabricates and assembles a large variety of electrical motors. Finally, several conclusions about the application of the scheme are given in the last section.

\section{PREVIOUS RESEARCH}

As mentioned previously, setup reduction is a key element in any improvement program. Decreasing setup time yields important benefits in productivity, response time, and flexibility. A setup reduction project will improve the overall performance of a production system provided that the machines to analyze are properly selected. Obviously, efforts should be focused on the setups that will yield the maximum gain, keeping in mind that there is a limited budget of resources. The purpose of the selection phase is to determine; which machines should be studied; what item setup must be reduced; and what sequence of setup projects should be implemented. A guideline to choose the best projects would be to seek for those machines with highest utilization, items with longest setup times and largest lot production runs (Steudel, et al 1992). Nicholas (1998) suggests to focus setup investment efforts to bottlenecks, though he does not provide a scheme or procedure. Chakravorty et al (1995) offers a general scheme 
based on Theory of Constraints (TOC) (Goldratt, et al 1990), and applies it to a theoretical example, assuming setup reduction projects leading to a 70\% reduction in setup times. Finally, Villarreal et al (2002) provide a TOC based procedure to prioritize setup reduction efforts and apply it in the machining department of a Mexican company. All these works are developed with the purpose of improving productivity and capacity utilization. Additionally, They treat the setup reduction problem isolated from the determination of lot sizes and the requirements of investments to implement them.

Most of the literature dealing with estimating or reducing manufacturing lead time is based upon the use of queueing models. Karmarkar et al (1992), Yang et al (1993), Dobson et al (1992), and Kekre (1987) focus on the impact of lot sizing on lead time. Kekre (1987) and Yang et al (1993) consider the impact of product mix and Karmarkar, et al (1992) discusses the relevance of order release mechanisms. Yang, et al (1993) provide guidelines to prioritize setup reduction efforts, according to product setups, for a closed manufacturing cell using M/G/1 queueing model. None discusses in detail how a reduction of setup time will affect the level of manufacturing lead time.

The previous works use models developed with queueing theory to treat setup reduction. Others such as Dobson et al (1992) describe the application of a GPSS simulation model of a manufacturing cell to analyze the effect of lot sizing on queueing delays and validate Q-LOTS, a general analytical model. Bard, et al (1999) use a simulation approach to estimate delays due to batching in a semiconductor facility. Finally, Atherton, et al (1995) employ simulation to estimate lot cycle times in a wafer manufacturing facility.

In this paper we are concerned with a plant that produces several items in a job shop with various work stations. Each product has a different sequence of processing, is produced in lots, and a setup is required in order to start its processing at each machine. The goal of the plant is to improve its response time to the market. In order to meet this goal, the firm is devising an improvement program of its manufacturing lead time, under a TOC scheme. A fundamental element of this program is a Setup Reduction Program in which shop floor and engineering personnel participate in the generation and implementation of projects. In this context, it is important to guide the improvement efforts, and determine and sequence those that contribute to the satisfaction of the firm's goal. The scheme must now be designed to prioritize projects according to their contribution towards the order winning factor. How to sequence the projects to improve the systems' average lead time? This aspect is treated in the following section.

\section{USING SIMULATION TO DEFINE A SETUP REDUCTION STRATEGY}

The purpose of the project was to improve the manufacturing lead time of the motor assembly area of Emerson de México, S.A. The company assembles a high variety of electrical motors in its plant located in Apodaca, N.L., México. The plant is divided into 6 fabrication areas:

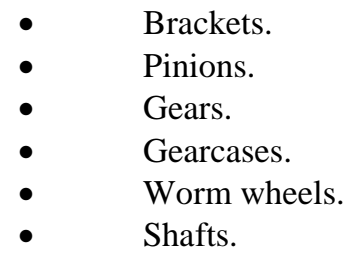

The layout and a view of the shop floor is shown in Figure No. 1.

\subsection{On Time Delivery Performance}

In order to measure the plant's performance in terms of delivery response, a total of 11345 orders were processed corresponding to a one year period. Of the total orders received 59\% were delivered late!! Original average order manufacturing lead time was estimated at 888 minutes. A goal of about 600 minutes was estimated to obtain a "zero delay" level. A detailed analysis of the contribution of its elements resulted in the identification that the shaft assembly operation was experiencing long delays that require an important reduction. Two product families 
are manufactured in the shaft area. These are the output shaft and worm shaft families. Observing the lead times for both families it was found that the output shaft family was impacting the most on lead time. The work described in this document is concerned with this family.

\subsection{Using Simulation to Analyze Shaft Assembly Lead Time}

After considering the possibility of developing queuing models to help management to identify areas of opportunity, it was finally decided that simulation would be a more flexible tool.

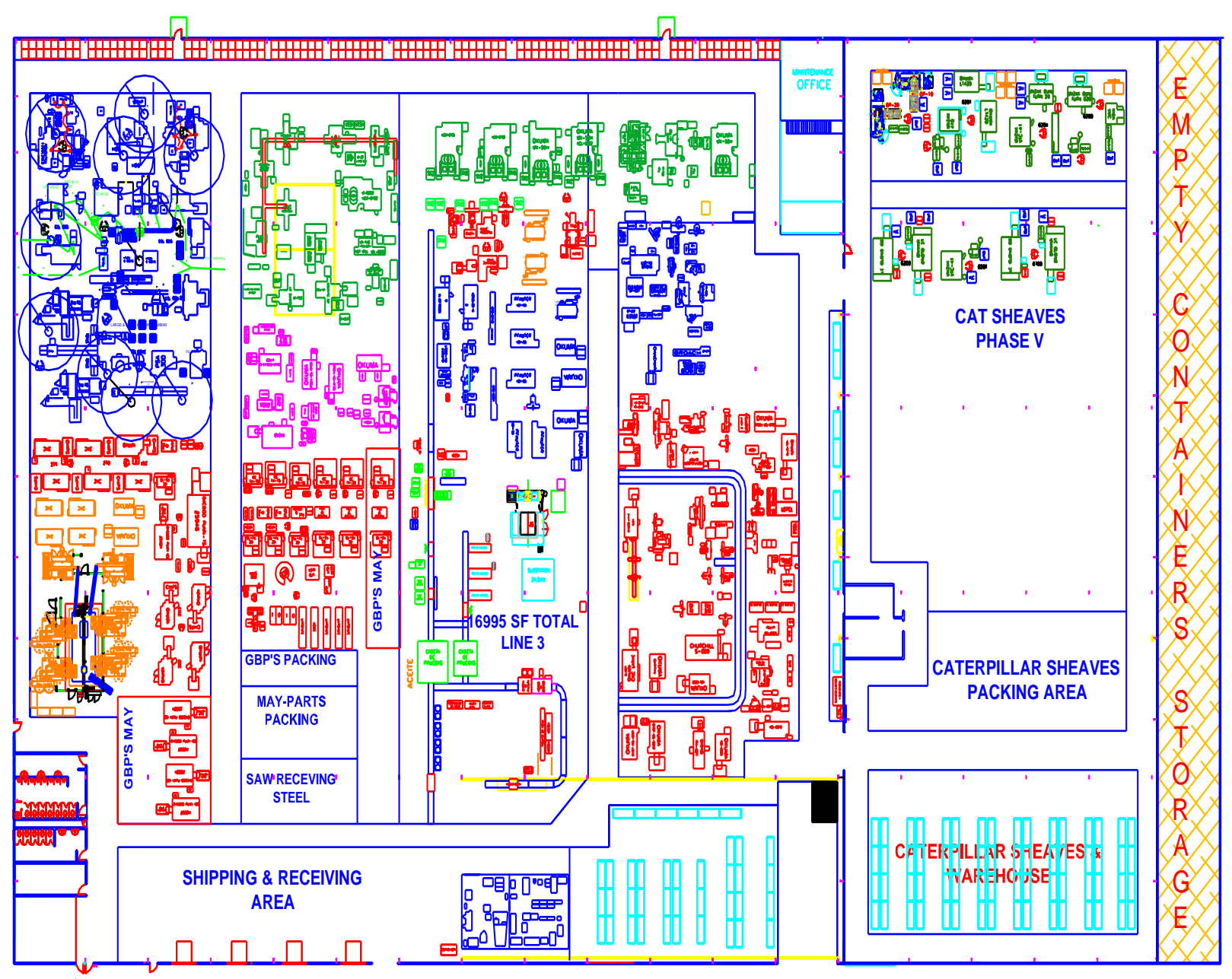

Figure No. 1. Layout of Shop Floor.

The next step was to develop a simulation model of the shaft assembly operations using Promodel software. The objective of the model was to assist management to identify the machines where a reduction of setup time would impact the most total manufacturing lead time. Since it was intuitively expected that the initial efforts should be invested on bottleneck machines, a machine load analysis was carried out concluding that the Captain and Okuma presses were the bottleneck machines. It was also found out that they employed an important proportion of time, about $46.7 \%$, carrying out setups.

It was then decided to use the simulation model to estimate the relationship of setup time reduction $\%$ and total manufacturing lead time. This relationship is shown in Figure No. 2 for the most important machines and it is represented by a piecewise linear function for each one. 
The main result obtained is that the rate of manufacturing lead time reduction is decreasing for each machine. Each machine's function, consists of several linear segments with different slope, being these lower as setup time is decreased. Given this behaviour, one can take advantage of each linear segment with different slope ranking them in descendent order as illustrated in Figure No. 3. It will be considered that the manufacturing lead time reduction achieved in each linear segment is a result of the implementation of a setup reduction "effort" consisting of a set of projects.

Sequence machines according to order flow time decrease per \% of setup time reduction (slope).

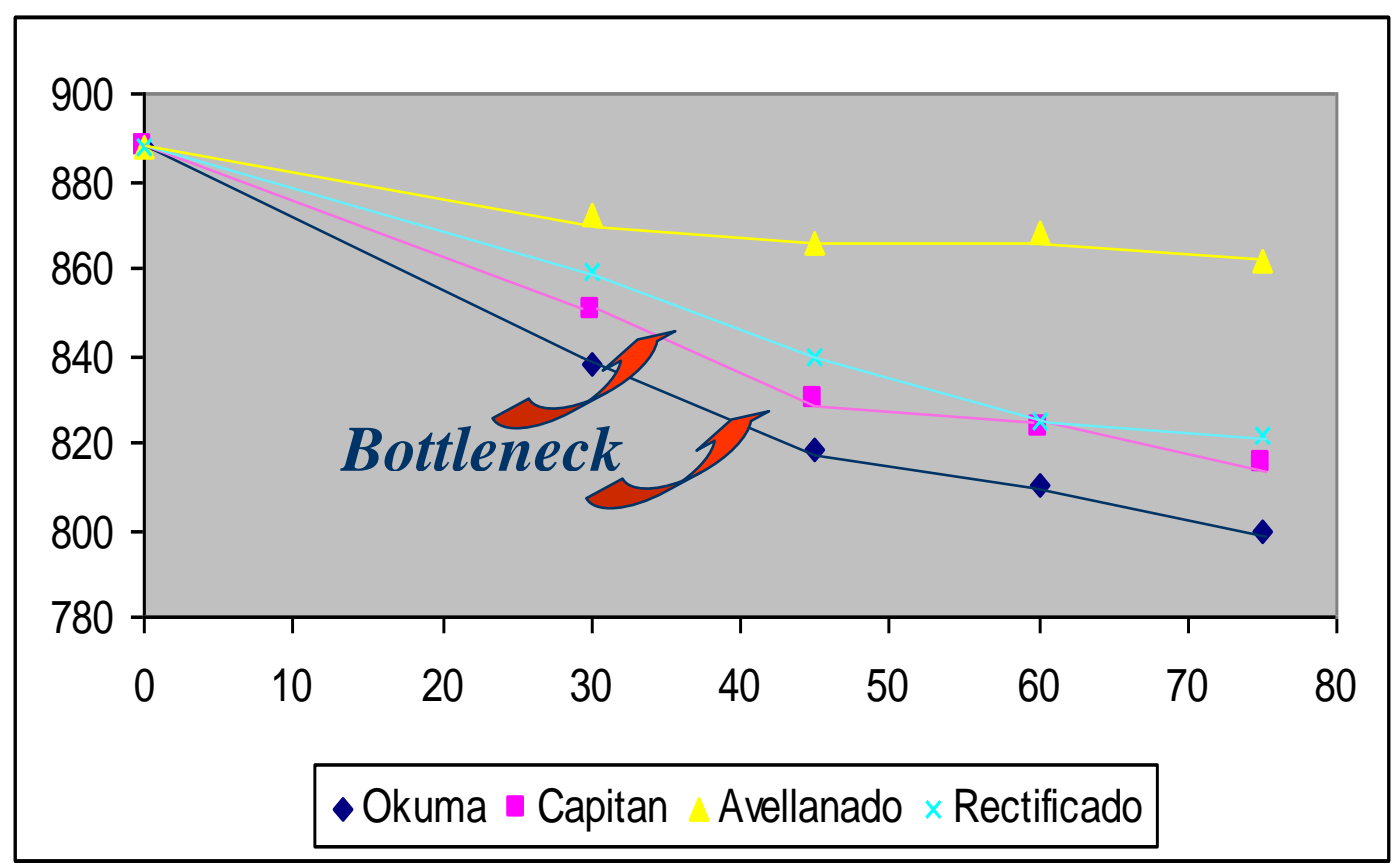

Figure No. 2. Behaviour of Manufacturing lead time and setup time reduction

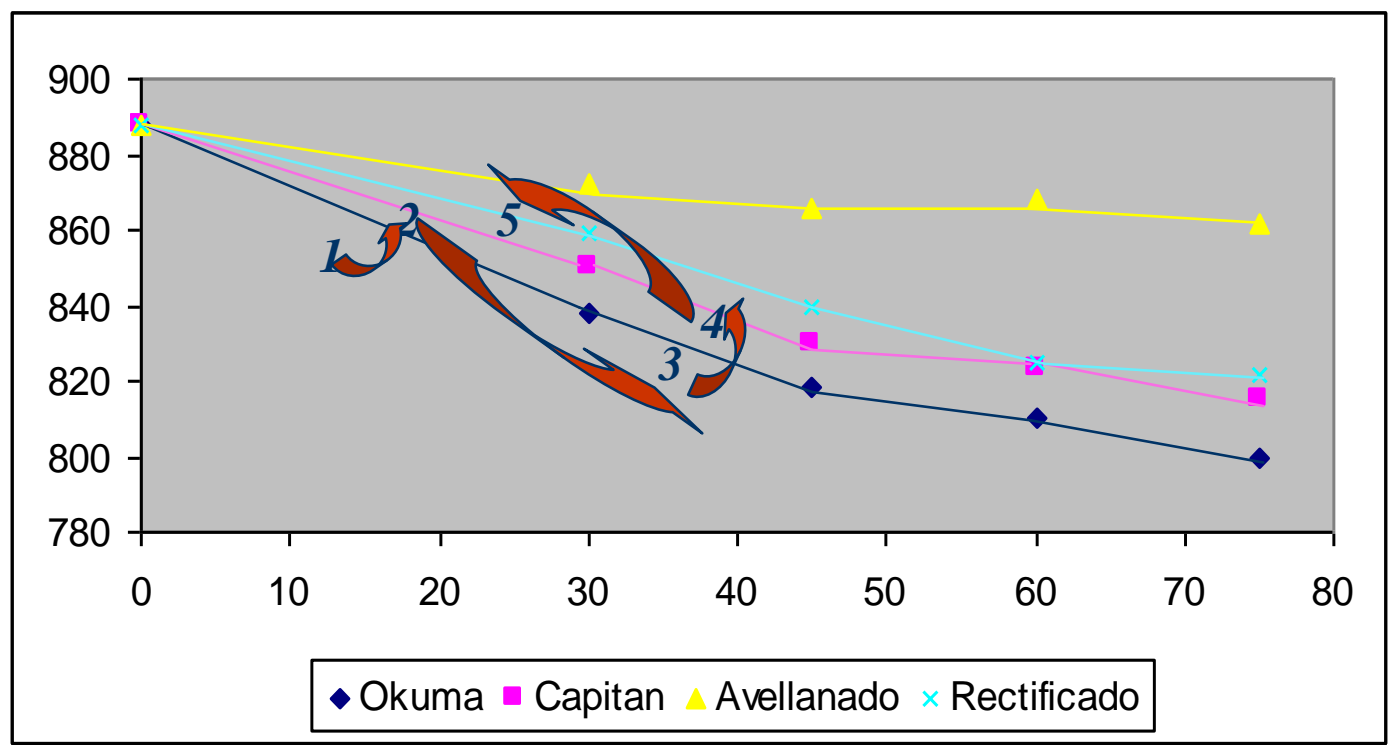

Figure No. 3 Sequence of setup reduction "efforts" 
According to the ranking, one should initiate the strategy for reducing total manufacturing lead time with an effort (No. 1) to decrease Okuma setup time up to 30\%. The next effort should be in the Captain machine decreasing setup time up to $30 \%$, then one should focus on decreasing setup time in Okuma, and so on. At this point, each set of projects associated with each "effort" has not being identified. This will de carried out with the procedure described in the next section.

The previous reasoning is used as the basis to define a procedure to determine the setup reduction strategy for the company.

\subsection{Procedure for Defining Setup Reduction Strategy}

The procedure employed to define the setup reduction strategy is described as follows.

- $\quad$ Organize teams to identify projects for each machine.

- Identify setup time decrease impact for each project and the required investment.

- $\quad$ Rank the projects in ascending order according to the required investment for each machine.

- $\quad$ Assign projects according to rankings to each effort, until budget restriction is enforced.

- Finally, every effort, with its corresponding set of projects, is ordered accumulating the required investments. This is done until a budget limit is met or the setup reduction goal is achieved.

Table No. 1 illustrates a sample of the ranking of projects for OKUMA press. Here, three projects are shown: A 5S's program, a new tool supply system and the repair of an optical comparator. A description of their contribution to OKUMA's setup time reduction is also given along with their assignment to a particular "effort". The $5 \mathrm{~S}$ 's program and the new tool supply system are included as part of "effort" 1 with a total investment of 1500 USdls.

Table No. 1. OKUMA Setup Reduction Projects.

\begin{tabular}{|c|l|c|c|c|}
\hline Project No. & \multicolumn{1}{|c|}{ Project } & \% Setup Time & Effort & Investment \\
\hline 1 & 5 S's program & 18 & 1 & -- \\
\hline 2 & New tool supply system & 10 & 1 & 1500 \\
\hline 3 & Repaired optical comparator & 12 & 3 & 4500 \\
\hline
\end{tabular}

Figure No. 4 illustrates both; the sequence of "efforts" and the assignment of projects to each effort. It is worth to notice that the suggested sequence may contain "efforts" applied to different machines. The definition of the sequence is restricted by a budget constraint or a desired setup time goal.

The impact of the strategy on manufacturing lead time is described in Figure No. 5. The result of implementing it shows a decreasing rate of lead time reduction. An important conclusion reached by management was that the desired goal of 600 minutes would not be achieved by the implementation of the setup reduction program alone. It was required to identify and implement additional projects such as the reduction of production lots, the establishment of one-piece flow manufacturing and others, to be able to meet the goal. 


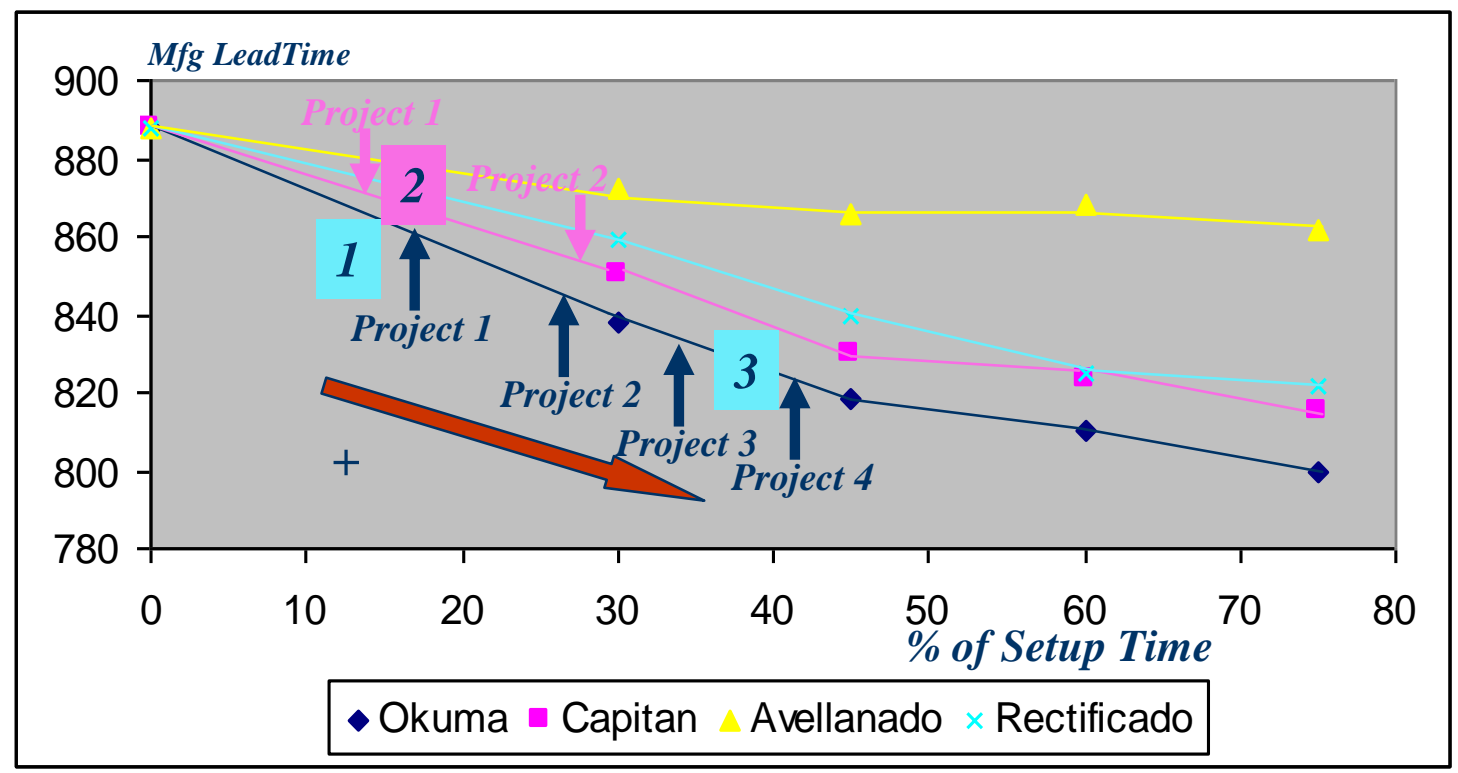

Figure No. 4. Assignment of projects to sequence of "efforts"

\section{CONCLUSIONS}

This paper offers a procedure based upon Theory of Constraints for identifying, prioritizing, sequencing and implementing setup reduction projects in a multi-product, multi-machine environment. It is conceived to be part of an improvement program in which there is high participation of shop floor and engineering personnel. Projects are conceptually designed, selected and implemented by these personnel according to a prior ranking based upon their generation of throughput.

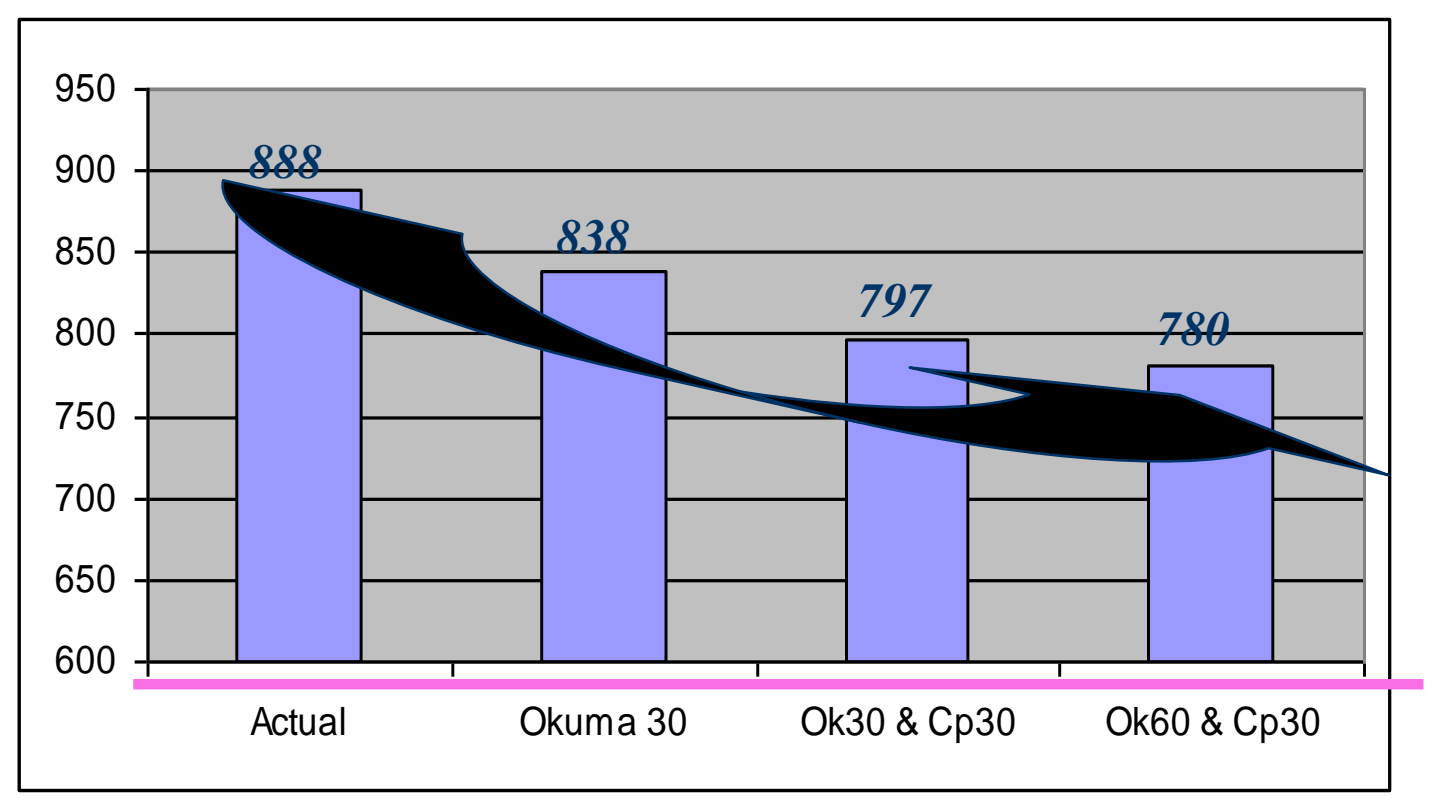

Figure No. 5. Impact of strategy on manufacturing lead time 
The procedure is applied in the shaft assembly department of a Mexican company. Simulation was a very helpful tool to craft a strategy and facilitate the understanding to everybody involved. The strategy included efforts sequenced according to their marginal contribution to order flow time reduction. The goal of 600 minutes for average order lead time could not be achieved only with setup time reduction.

\section{REFERENCES}

1. Atherton, L.F. and Atherton, R.W., (1995), Wafer Fabrication: Factory Performance and Analysis, Kluwer, Boston.

2. Bard, J.F., Srinivasan, K. and Tirupati, D., (1999) An Optimization Approach to Capital Expansion in Semiconductor Manufacturing, International Journal of Production Research, Vol. 37, No. 15.

3. Chakravorty, S.S. and Sessum, J.L., (1995), Developing Effective Strategies to Prioritize Set-up Reduction in a Multi-machine Production System: A Throughput Approach, International Journal of Operations and Production Management, Vol. 15, No.10.

4. Dobson, G., Karmarkar, U.S. and Rummel, J., (1992), A Closed Loop Automatic Scheduling System (CLASS), Production Planning and Control, Vol. 3, No. 2.

5. $\quad$ Goldratt. E.M., Theory of Constraints, (1990), North River Press, Croton-on-Hudson, N.Y.

6. Hall, R.W., (1983), Zero Inventory, Business One Irwin, Homewood, Il.

7. Karmarkar, U.S., Kekre, S. and Kekre, S., (1992), Multi-item Batching Heuristics for Minimization of Queueing Delays, European Journal of Operational Research, Vol. 52.

8. Kekre, S., (1987), Performance of a Manufacturing Cell with Increased Product Mix, IIE Transactions, Vol. 19.

9. Nagel, R. and Dove, R., (1991), $21^{\text {st }}$ Century Manufacturing Enterprise Strategy, Iacocca Institute, Lehigh University.

10. Nicholas, J.M., (1998), Competitive Manufacturing Management, IRWIN/McGraw Hill.

11. Shingo, S., (1985), A Revolution in Manufacturing: The SMED System, Productivity Press, Stamford, CT.

12. Steudel, H.J. and Desruelle, P., (1992), Manufacturing in the Nineties, Van Nostrand Reinhold.

13. Villarreal, B., Reyes, R. and Sahagun, Ch, (2002), Applying a TOC Strategy to Setup Reduction, Proceedings of 2002 POMS Conference, San Francisco, CA.

14. Yang, J. and Deane, R.H., (1993), Setup Time Reduction and Competitive Advantage in a Closed Manufacturing Cell, European Journal of Operational Research, Vol. 69. 
NOTES 